\title{
Erratum to: Novel immunoregulatory role of perforin-positive dendritic cells
}

\author{
$\operatorname{Ran}_{\text {Orgad }^{1}}{ }^{\text {Bar Nathansohn-Levi }}{ }^{1} \cdot$ Sivan Kagan ${ }^{1} \cdot$ Yael Zlotnikov Klionsky $^{1}$. \\ Yair Reisner $^{1}$
}

Published online: 17 November 2016

(C) Springer-Verlag Berlin Heidelberg 2016

Erratum to: Semin Immunopathol

DOI: 10.1007/s00281-016-0589-6

The name of the fourth author, Yael Zlotnikov Klionsky, was unfortunately omitted from the original publication during typesetting but has now been restored. The publisher apologizes for this error.

The online version of the original article can be found under doi:10.1007 /s00281-016-0589-6

\footnotetext{
Yair Reisner

Yair.Reisner@weizmann.ac.il

1 Department of Immunology, Weizmann Institute of Science,

Rehovot, Israel
} 